\title{
Effects of Planting and Maturity Dates on Shattering Patterns under Early Soybean Production System
}

\author{
Lingxiao Zhang $^{{ }^{*}}$, Nacer Bellaloui ${ }^{2}$ \\ ${ }^{1}$ Chemistry Research Unit, Center for Medical, Agricultural \& Veterinary Entomology, USDA-ARS, Gainesville, USA; ${ }^{2}$ Crop Ge- \\ netics Research Unit, USDA-ARS, Stoneville, USA. \\ Email: "lingxiao.zhang@ars.usda.gov
}

Received October $13^{\text {th }}$, 2011; revised November $9^{\text {th }}$, 2011; accepted November $29^{\text {th }}, 2011$

\begin{abstract}
Seed shattering is a common problem in early soybean production system (ESPS) in the Midsouth, which mainly uses maturity group (MG) IV soybeans. Many studies have been conducted on the genetics of soybean shattering resistance for individual varieties; however, information on the physiology of soybean shattering pattern under specific environmental conditions, which is often critical to soybean growers, is very limited. Field experiments were conducted at Stoneville MS from 2007 to 2009 to investigate the shattering patterns of 80 - 132 MG IV soybean varieties each year. Results from 2007 and 2008 indicated that, when April-planted MG IV soybeans matured in mid- to late-August, pods of most soybean varieties did not shatter within the first three weeks after maturity (WAM) and there was no significant shattering effect on final yields. However, differences in pod shattering among the varieties became apparent in the fourth WAM. Late-planted MG IV soybeans, which matured in early September, had a low shattering rate and could hold seeds up to 6 WAM before reaching a critical shattering point. Most soybean varieties planted in April 2009 did not show significant pod shattering by the end of the fourth WAM. The critical point of shattering was not reached until 6 - 7 WAM. Relatively lower temperatures and abundant rainfall during the late growing season in 2009 may be the main reasons causing delayed shattering in April-planted MG IV soybeans. Results from the May-planting of 2007 and the April-planting of 2009 indicated that soybeans maturing after September have much less problematic shattering. Different weather patterns, especially temperature and rainfall in each year could be essential factors affecting seed shattering patterns.
\end{abstract}

Keywords: Soybean; Shattering; Maturity Group; Planting Date; Weather

\section{Introduction}

Drought stress is often a serious problem in soybean production and it is one of the major factors limiting yield, especially in areas with limited water resources. In these areas rain-fed soybean production system is common. Some early maturing soybeans may adapt well into these regions that drought stress often occurs. However, delaying harvest of the early maturing soybeans often cause serious yield reduction due to severe seed shattering $[1,2]$.

Soybean shattering was not a critical issue with conventional soybean production in Mississippi and the Midsouth in the 1970s and 1980s, when majority of the soybean grown were maturity groups (MG) VI or later, and planted in late May and June. Since the early soybean production system (ESPS) was introduced and adopted in Mississippi and the Midsouth in the early 1990s [3], MG IV soybean has become the domin-

${ }^{*}$ Corresponding author. ant group in the ESPS. An MG IV soybean variety grown under the ESPS is usually planted in April and mature from mid-August to early September in Mississippi [4], depending on the sub-MG, planting dates, precipitation, and temperature. As a consequence, the seed maturing process and the period thereafter often occur under heat-stress. On the other hand, many growers may not be able to harvest matured soybeans on time due to various reasons such as unfavorable weather conditions or labor and machinery shortage. Many growers in the Midsouth who grow soybean under irrigation also grow rice that matures at the same time as the MG IV soybeans. Therefore, the conflict between harvesting times often delays soybean harvest due to the higher crop value of rice.

Seed shattering is considered as one of the major problems for soybean growers under the ESPS conditions [5]. Previous studies indicated that there were significant differences in shattering resistance among different va- 
rieties [6,7] and the characteristic of seed shattering is genetically controlled $[6,8,9]$. Other studies have also shown that each soybean variety has its specific genetic background that controls its shattering resistance [10-12]; however, within the same maturity group, soybeans respond similarly to environmental factors and cropping practices such as temperature, precipitation, planting dates, harvesting times, etc. [13]. New soybean varieties with better shattering resistance can improve yield up to 50\%, compared with the old varieties [14].

In recent years, soybean varieties have been developed at a very fast pace and the average life span of a commercial variety is only about five years. Therefore, it is obvious that studying shattering characteristics of an individual variety may not be particularly meaningful to soybean growers. Under this circumstance, studying the patterns and dynamic of seed shattering under specific circumstances, such as under ESPS, may be more relevant to help growers to overcome the problem.

Since information on shattering is very limited, an understanding of soybean shattering pattern and dynamics is essential to minimize yield loses in the ESPS in Mississippi. The current research responded to the following important questions: 1) which factor (or factors) plays a major role in seed shattering? 2) How does the interaction between various factors (such as planting date, maturity date, precipitation or soil moisture, and temperature) play a role in the seed shattering process? These questions were addressed by: 1 ) investigating shattering patterns and their associated characteristics under different production systems and environmental conditions, and 2) identifying which factor was the main contributor to seed shattering of MG IV soybeans under ESPS.

\section{Materials and Methods}

Experiments were conducted in 2007, 2008 and 2009 at Stoneville, MS (lat. $33.4^{\circ} \mathrm{N}$, long. $90.9^{\circ} \mathrm{W}$ ). The tested varieties were selected from the variety list of Mississippi soybean official variety trials (OVT) of the corresponding years [15-17]. All the varieties were provided by public institutes and various private seed companies. The soybean varieties listed in the OVT during a particular year would most likely serve as the major variety selection source for state soybean growers the following planting season. Since MG IV soybeans are mainly used in the ESPS, soybeans varieties from MG IV (MG 4.0 4.9) were examined in this study.

In 2007 and 2008, field plots followed the conventional field practice procedures used in Mississippi soybean OVT [16,17], which plotted approximately $5 \mathrm{~m}$ length by $0.5 \mathrm{~m}$ row-space with $0.05 \mathrm{~m}$ interplant distance, except only 2-row plots were used (instead of 4row plot in the OVT). In these experiments, four repli- cates were arranged (instead of three replicates in the OVT) with a randomized complete block design (RCBD).

In 2007, experiments were conducted on irrigated and non-irrigated fields adjacent to the Mississippi OVT sites. Seeds were planted on April 17 (April-planting) on both fields. A second planting was done on May 9 (Mayplanting) on the irrigated field. Eighty (80) MG IV varieties were planted in these experiments. In 2008, a repeated experiment was conducted only on irrigated field and only for April-planting (April 23) with the same 80 varieties used in 2007.

In 2009, 132 MG IV soybean varieties were evaluated directly utilizing the Mississippi OVT plots established at Stoneville, MS [15]. Soybeans were planted on both irrigated and non-irrigated fields on April 24 (April-planting). The configuration of original plots was 4-row with $5 \mathrm{~m}$ length, $0.5 \mathrm{~m}$ row-spacing and $0.05 \mathrm{~m}$ interplant distance. The experiment was arranged in a RCBD with three replications. After seed maturity, the middle two rows were harvested for seed yield and the outside two rows were used for shattering evaluation.

\section{Data Collection, Adjustment and Analysis}

In all three years, soybean shattering status for each variety was visually estimated at weekly intervals starting from two weeks after maturity (WAM) until six to seven WAM. The evaluation criteria have been described by Zhang and Boahen [18] and summarized in Table 1. No yield data were collected directly from the experimental plots for 2007 and 2008; however, yield data from the OVT plots at Stoneville location (with the same varieties planted at similar time and adjacent to these experiments) were used to examine the relationship between seed shattering and yield potential of each variety.

Data were analyzed using Proc Mixed Model of SAS program and the differences between means was separated with LSD at a $=0.05$ level. The homogeneous analysis has performed for the individual years and the results were varied greatly, most likely due to environmental conditions of each year. Therefore, data was analyzed and reported separately.

\section{Results and Discussion}

In 2007, shattering patterns of soybean varieties planted in April on non-irrigated and irrigated fields showed some differences. On the non-irrigated field, plants sown in April matured between August $13^{\text {th }}$ and August $21^{\text {st }}$ with a mean maturity date of August $16^{\text {th }}$. Thirty seven and half percent (37.5\%) of the varieties held seeds very well (shattering rate of $5 \%$ or less) and $51.2 \%$ of varieties held seeds relatively well (shattering rate of $6 \%-14 \%$ ) at 3.5 WAM (Table 2). However, at 4.5 WAM, only $11.3 \%$ of varieties still held seeds with less than $15 \%$ shattering 
Table $1^{*}$. Criteria and description used for estimation of the percentages of soybean shattering status in a plot. A 2-row plot is used and the plot length is $5 \mathrm{~m}$ long with $0.5 \mathrm{~m}$ row-spacing and $0.05 \mathrm{~cm}$ inter-plant distance.

\begin{tabular}{|c|c|c|}
\hline Scale & $\%$ of shatter & Criteria and observational description \\
\hline 1 & 0 & Absolutely no shattered pod \\
\hline 2 & 2 & Five or less shattered pods are observed in a plot \\
\hline 3 & 5 & More than five but less than 15 shattered pods are observed and they are mostly on the top of the plants \\
\hline 4 & 10 & $\begin{array}{l}\text { More than } 15 \text { shattered pods are observed, but it is estimated at } 10 \% \text { or less of whole pods in the plot. A few shattered pods } \\
\text { are in the upper middle or middle of the stems }\end{array}$ \\
\hline 5 & 15 & $\begin{array}{l}\text { Many top pods are shattered and some of the lower portions of the pods are also shattered. This is considered as a critical } \\
\text { stage that has a significant effect on seed yield }\end{array}$ \\
\hline 6 & $20-30$ & $\begin{array}{l}\text { Almost all the top pods were shattered, and shattered pods on } 1 / 4 \text { of the plants. Pods shattering more than } 25 \% \text { results in } \\
\text { severe yield loss }\end{array}$ \\
\hline 7 & $35-50$ & All top pods shattered, and the shattered pods went down to the middle part of the plant \\
\hline 8 & $60-100$ & Most of the pods are shattered \\
\hline
\end{tabular}

*Adopted from Zhang and Boahen, 2010.

Table 2. Three-year comparison of shattering status at approximately four weeks after maturity (WAM) for MG IV soybeans at Stoneville, Mississippi in 2007-2009 ${ }^{\dagger}$.

\begin{tabular}{|c|c|c|c|c|c|c|c|}
\hline \multirow{3}{*}{$\begin{array}{c}\text { Month/Year } \\
\text { WAM }\end{array}$} & \multicolumn{3}{|c|}{ April 2007} & \multirow{3}{*}{$\begin{array}{c}\text { May } 2007 \\
\text { Irrigated } \\
4\end{array}$} & \multirow{3}{*}{$\begin{array}{c}2008 \\
\text { Irrigated } \\
4\end{array}$} & \multirow{2}{*}{\multicolumn{2}{|c|}{$\begin{array}{c}2009 \\
\text { Irrigated }\end{array}$}} \\
\hline & \multicolumn{2}{|c|}{ Non-irrigated } & \multirow{2}{*}{$\begin{array}{c}\text { Irrigated } \\
4\end{array}$} & & & & \\
\hline & 3.5 & 4.5 & & & & 3.5 & 4.5 \\
\hline \multicolumn{8}{|c|}{ Shattering rate } \\
\hline $0-5 \%$ & $30(37.5)$ & $1(1.3)$ & 15 (18.8) & 45 (56.3) & 17 (21.2) & $114(86.4)$ & 69 (52.3) \\
\hline $6 \%-14 \%$ & $41(51.2)$ & $8(10.0)$ & $42(52.5)$ & $23(27.5)$ & 39 (48.8) & $11(8.3)$ & 39 (29.5) \\
\hline$=/>15 \%$ & $9(11.3)$ & 71 (88.7) & $23(28.8)$ & $12(16.2)$ & $24(30.0)$ & $7(5.3)$ & $24(18.2)$ \\
\hline
\end{tabular}

${ }^{\dagger}$ Data in the table are number of varieties in each shattering rate category. Total variety numbers are 80,80 and 132 for 2007,2008 and 2009 , respectively. The number in parenthesis indicates the percentage of total.

(Table 2). On the irrigated field, plants matured from August $14^{\text {th }}$ to August $28^{\text {th }}$ with a mean maturity date of August $21^{\text {st }}$. For the plants sown in April and grown under irrigation, about $18.8 \%$ of the varieties held seeds very well whereas $52.5 \%$ of the varieties held seeds relatively well at 4 WAM. However, $28.8 \%$ of varieties shattered $15 \%$ or more (Table 2). In contrast, for irrigated May-planting, plants matured from September $5^{\text {th }}$ to September $17^{\text {th }}$ with a mean maturity date on September $10^{\text {th }}$. Seed shattering was not significant with a 56.3 $\%$ of varieties still holding seeds very well at 4 WAM. Plants of most varieties did not show significant shattering (over 15\%) until about 6 WAM (Figure 1).

The above results indicated that the $4^{\text {th }}$ WAM was a critical shattering point for MG IV soybeans planted between mid- to late April in Stoneville Mississippi, when seeds matured in mid- to late-August. However, if the seeds matured in early- or mid-September such as in the May-planting, seeds could be held in the pod well and shattering would not be a serious problem if the harvest was done within a month.

The shattering pattern in 2008 was similar to that for the previous year, in which most irrigated soybean varie-

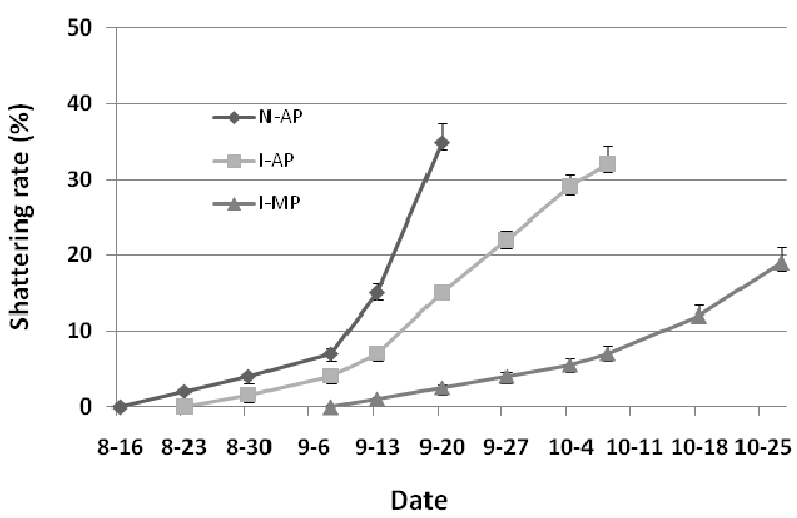

Figure 1. Comparison of shattering patterns of MG IV soybeans between irrigated non-irrigated and irrigated Aprilplantings (N-AP \& I-AP, respectively; planted on April 17) and irrigated May-planting (I-MP, planted on May 9) in 2007. Data points were the means of 80 varieties.

ties planted in April and May held seeds well for the first three weeks after maturity. However, the major difference appeared four weeks after maturity (Table 2). Due to excessive rainfall during the later part of the 2008 growing season, shattering scores beyond four WAM 
could not be assessed. Therefore, shattering pattern for 2008 season was not available for comparison.

Maturity dates of soybean varieties within the same MG can be varied from 10 to 15 days depending on the time of planting and location [18,19]. Therefore, using the 2009 data, varieties were further grouped into early and late MG IV. For most early or late MG IV varieties, very limited shattering was observed even at the end of the $4^{\text {th }}$ WAM (Figure 2). The critical shattering point of $15 \%$ was not reached until at $6-7 \mathrm{WAM}$ or later. Among the 132 MG IV varieties used, only $5.3 \%$ of the varieties had $15 \%$ or more shattering at 3.5 WAM, but shattering increased to $18.2 \%$ at 4.5 WAM (Table 2). However, there were still more than half $(52.3 \%)$ of the varieties holding seed very well (5\% or less shattering) at the end of 4.5 WAM. Overall, the data from 2009 revealed a similar shattering pattern for both early and late MG IV soybeans (Figure 2), which showed little shattering within three to four WAM, but shattering increased after four WAM. Compared with the results of soybean planted in April 2007 on irrigated field (Figure 1), the rate of increase in shattering and the time to reach $15 \%$ shattering score were much slower in 2009. The MG V varieties were also investigated and had a similar pattern comparison with MG IVs. However, since MG V soybeans were not the major focus of this study, results are not presented here.

Comparing the seed shattering patterns between irrigated and non-irrigated April-plantings during the first three WAM in 2007, soybean plants showed similar trends of very limited shattering. However, after three WAM, non-irrigated soybeans shattered at a much faster pace than that of irrigated soybeans (Figure 1). May planted soybeans held seeds better after maturity than both irrigated and non-irrigated April-plantings. However, due to excessive rainfall during the late season in 2009, no significant growth difference occurred between the irrigated and non-irrigated fields. Therefore, data on

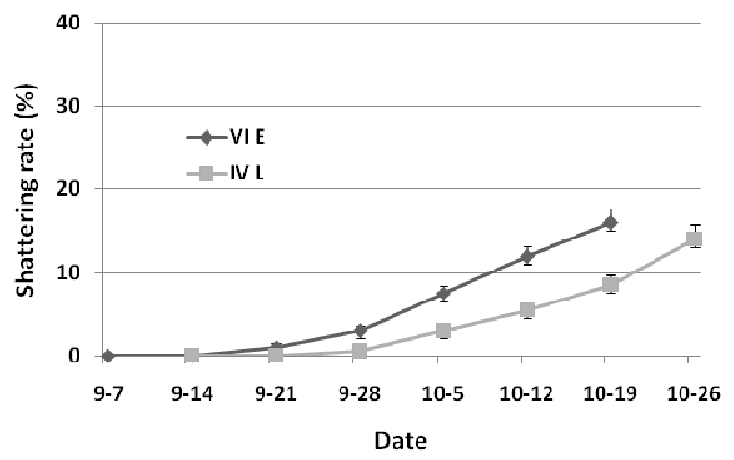

Figure 2. Comparison of times to critical shattering point (15\%) between early MG IV (IV E), and late MG IV (IV L) soybeans in 2009. Planting date was on April 24. Data points represent means of 132 varieties. non-irrigated fields were discarded. Philbrook and Oplinger [1] considered $10 \%$ seed shattering as a critical point that affect yield significantly in the Midwest; therefore, they suggested a critical harvest time within two weeks after maturity. Based on this study, soybean seed matured under ESPS in the Midsouth should still be able to hold seeds for at least three WAM before reaching that 10\% critical point (Figure 1).

For both irrigated April-plantings of 2007 and 2009, the difference between planting dates was only a week (April 17 vs April 24), but the difference between maturity dates was more than two weeks (August 21 vs September $7^{\text {th }}$ ). This difference should be the main reason, in addition to weather difference, resulting in different shattering patterns of 2007 and 2009. It may be possible that the extended one week growing period in 2009 influenced the shattering patterns of April-planting; more importantly the extended growth duration ending within late August and early September. If this one-week delay in maturity occurred during the mid- or late-September, shattering pattern would not be that significant. The delay in seed shattering in 2009 was mainly caused by precipitation and temperature. The period from early September to late October in 2009 consisted of cool temperatures (Figure 3) and abundant moisture (Figure 4) during the post seed-maturing time, providing a very favorable environment to retain seeds in the pods. The early and late MG IV soybeans of 2009 mostly matured in early to mid-September while those of 2007 mostly matured between mid- and late-August. In 2009, there were still about $40 \%$ late MG IV soybean varieties, compared with $21 \%$ in early MG IVs with less than $15 \%$ shattering at the end of 6 WAM. This indicated that when seed matured in September, shattering was delayed and seed could be held in the pods longer. Thus, the timing of seed maturity may be more important with regards to shattering patterns than the planting date or type of soybean MGs.

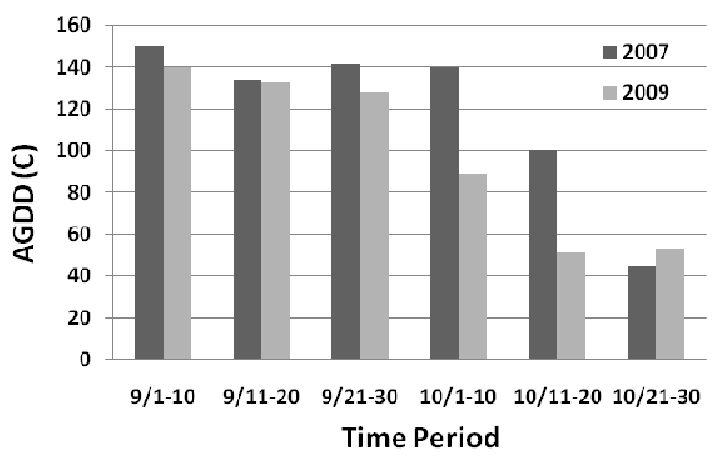

Figure 3. Comparison of the accumulative growing degree day (AGDD) of late growing season at Stoneville, Mississippi in 2007 and 2009. The AGDD is an indication of effective temperature in soybean growth. 


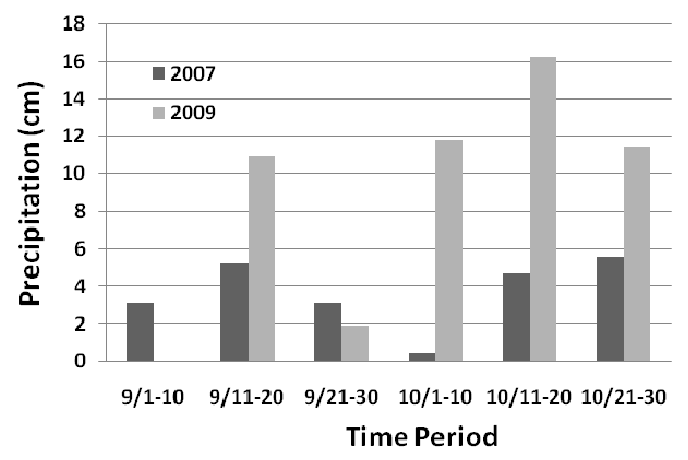

Figure 4. Precipitation during the late growing season at Stoneville, MS in 2007 and 2009.

The shattering pattern of irrigated April-planting soybean in 2009 was very similar to that of May-planting on the irrigated field in 2007, which both showed a slow increase of shattering rate. Though these two groups of plants were not planted at the same time period, they happened to have a very similar maturity time, in early September (Figures 1 and 2). This may indicate that the timing of seed maturity may be more important than the planting date or type of soybean MGs with regards to shattering patterns. Hence, it may be necessary to recommend to growers to purposely plant their soybeans aimed at maturity date around early September if shattering is a concern.

In both 2007 and 2009, no significant correlation was found between seed shattering of an individual variety and its yield (data not shown). This was somewhat expected due to the fact that majority OVT tests were harvested before significant seed shattering occurred. Meanwhile harvest delay could occur at any time under wet conditions, and may cause significant yield reductions.

Many other factors can affect harvest losses. These include row width [20], crop condition [21], weed infestations [13,22], and machinery [23]. However, little information is available on the effect of weather pattern affecting on soybean shattering, especially the rainfall effect on delaying crop growth and development and subsequent influence on soybean shattering patterns. Results from this study can help us to thoroughly understand the phenomenon of seed shattering under ESPS and provide proper recommendations to soybean growers in Mississippi and the Midsouth. Information from this study can also help to understand soybean shattering related issues in other regions since it is also a common problem occurring in soybean production.

In summary, soybean shattering was not a serious problem within the first three WAM when MG IV soybeans were grown under ESPS in Mississippi. However, shattering accelerated in the $4^{\text {th }}$ week when the plants matured in August, a period with relatively high temperatures and dry conditions. Planting time may not be a critical issue but the time of seed maturity is a key factor that can influence pod shattering. Delayed planting and using relatively late MG (such as late IV) are management options that could be practiced to shift the time of maturity from August to September in order to minimize pod shattering. In certain years, as in 2009, the weather conditions can also alter the seed maturity time.

Further studies are required to answer the following questions: 1) To what extent can pod shattering resistance be improved through enhancing the plant genetic background? and 2) If early soybeans planted in early April or March mature before mid- and late-August, will they be able to hold seeds for three WAM?

\section{Acknowledgements}

The study was supported by Mississippi Soybean Promotion Board.

\section{REFERENCES}

[1] B. Philbrook and E. S. Oplinger, "Soybean Field Losses as Influenced by Harvest Delays," Agronomy Journal, Vol. 81, No. 2, 1989, pp. 251-258. doi:10.2134/agronj1989.00021962008100020023x

[2] P. Tukamuhabwa, K. E. Dashiell, P. Rubaihayo and M. Nabasirye, "Determination of Field Yield Loss and Effect of Environment on Pod Shattering in Soybean," African Crop Science Journal, Vol. 10, No. 3, 2002, pp. 203-209.

[3] L. G. and S. R. Spurlock, "Yield and Economics of Traditional and Early Soybean Production System (ESPS) Seedings in the Midsouthern United States," Field Crops Research, Vol. 63, No. 1, 1999, pp. 35-45.

[4] L. X. Zhang, J. Zhang, S. Kyei-Boahen and C. E. Watson Jr., "Developing Phenological Prediction Tables for Soybean,” Crop Management, 2004. doi:10.1094/CM-2004-1025-01-RS

[5] L. G. Heatherly, "Early Soybean Production System (ESPS)," In: L. G. Heatherly and H. F. Hodges, Eds., Soybean Production System in the Midsouth, CRC Press, Boca Raton, 1999, pp. 103-115.

[6] C. E. Caviness, "Heritability of Pod Dehiscence and Its Association with Some Agronomic Characters in Soybeans," Crop Science, Vol. 9, No. 2, 1969, pp. 207-209. doi:10.2135/cropsci1969.0011183X000900020029x

[7] R. Misra, S. Singh, S. Sharma and S. Mehta, "Note on Induced Variation in Shattering Habit of Soybean," Indian Journal of Agricultural Sciences, Vol. 51, No. 9, 1980, pp. 678-680.

[8] M. A. Bailey, M. A. R. Mian, T. E. Carter, D. A. Ashley and H. R. Boerma, "Pod Dehiscence of Soybean: Identification of Quantitative Trait Loci,” Journal of Heredity, Vol. 88, No. 2, 1997, pp. 152-154.

[9] L. A. Saxe, C. Clark, S. F. Lin and T. A. Lumpkin, "Mapping the Pod-Shattering Trait in Soybean," Soybean Genetics Newsletter, Vol. 24, 1996, pp. 250-253. 
[10] M. Suzuki, K. Fujino and H. Funatsuki, “A Major Soybean QTL, qPDH1, Controls Pod Dehiscence without Marked Morphological Change,” Plant Production Science, Vol. 12, No. 2, 2009, pp. 217-223. doi:10.1626/pps.12.217

[11] T. Tsuchiya, "Studies on Shattering Resistance in Soybean Glycine Max Breeding," Report of Hokkaido Prefectural Agricultural Experiment Station, Vol. 58, 1986, pp. 1-53.

[12] T. Tsuchiya, "Physiological and Genetic Analysis of Pod Shattering in Soybean,” Japan Agricultural Research Quarterly, Vol. 21, No. 3, 1987, pp. 166-175.

[13] O. C. Burnside, G. A. Wicks, D. D. Warnes, B. R. Somerhalder and S. A. Weeks, "Effect of Weeds on Harvesting Efficiency in Corn, Sorghum, and Soybeans," Weed Science, Vol. 17, No. 4, 1969, pp. 438-441.

[14] H. Tefera, A. Y. Kamara, B. Asafo-Adjei and K. E. Dashiell, "Improvement in Grain and Fodder Yields of Early-Maturing Promiscuous Soybean Varieties in the Guinea Savanna of Nigeria,” Crop Science, Vol. 49, No. 6, 2009, pp. 2037-2042. doi:10.2135/cropsci2009.02.0081

[15] B. Burgess, T. Koger, F. Boykin. J. Coccaro, E. Flint, R. Martin, J. Phelps, D. Reginelli, D. Respess, D. Rowe. G. Sciumbato, M. Silva, A. Smith and L. X. Zhang, "Mississippi Soybean Variety Trials, 2009,” Mississippi Agricultural and Forestry Experiment Station Information Bulletin, Vol. 454, 2010.

[16] B. White, A. Blaine, F. Boykin, B. Burgess, P. Gerard, J. Coccaro, R. Martin, D. Poston, D. Reginelli, D. Rowe, A. Smith, M. Young and L. X. Zhang, "Mississippi Soybean Variety Trials, 2007,” Mississippi Agricultural and Forestry Experiment Station Information Bulletin, Vol. 440,
2008.

[17] B. White, T. Allen, F. Boykin, B. Burgess, D. Ingram, D. Rowe, B. Johnson, E. Larson, R. Martin, S. Soignier, J. Singleton, A. Smith and L. X. Zhang, "Mississippi Soybean Variety Trials, 2008,” Mississippi Agricultural and Forestry Experiment Station Information Bulletin, Vol. 449, 2009.

[18] L. Zhang and S. Boahen, "Evaluation of Critical Shattering Time of Early-Maturity Soybeans under Early Soybean Production System," Agriculture and Biology Journal of North America, Vol. 1, No. 4, 2010, pp. 440-447. doi:10.5251/abjna.2010.1.4.440.447

[19] T. Tsuchiya and K. Sunada, "Breeding Studies on Pod Shattering in Soybeans. II. Methods of Testing for Shattering and Varietal Differences,” Soybean, Vol. 3, No. 12, 1980, p. 1706.

[20] W. R. Nave and R. L. Cooper, "Effect of Plant Population and Row Width on Soybean Yield and Harvesting Loss," Transactions of the American Society of Agricultural Engineers, Vol. 17, 1974, pp. 801-804.

[21] C. R. Weber and W. R. Fehr, "Seed Yield Losses from Lodging and Combine Harvesting in Soybeans," Agronomy Journal, Vol. 58, No. 3, 1966, pp. 287-289. doi:10.2134/agronj1966.00021962005800030012x

[22] W. R. Nave and L. M. Wax, "Effect of Weeds on Soybean Yield and Harvesting Efficiency," Weed Science, Vol. 5, 1971, pp. 533-535.

[23] E. S. Oplinger, J. P. Wright and A. Klassy, “A Plot Planting System Utilizing a Rear-Engine Tractor,” Agronomy Journal, Vol. 75, No. 5, 1983, pp. 848-850. doi:10.2134/agronj1983.00021962007500050029x 